\section{Variation in dietary intake and physical activity pattern as predictors of change in body mass index (BMI) Z-score among Brazilian adolescents*}

\section{Variação da ingestão dietética e do padrão de atividade física como preditores da mudança do escore- $z$ do Índice de Massa Coporal (IMC) entre adolescentes brasileiros}

\section{Carla C. Enes'}

\section{Betzabeth Slater"}

'School of Nutrition, Pontifical Catholic University of Campinas (PUC) Campinas, Brazil

" Department of Nutrition, School of Public Health, University of Sao Paulo, Sao Paulo, Brazil

* Financial resources granted by the State of Sao Paulo Research Support Foundation (FAPESP) (no. 02/9521-9).

Corresponding author: Carla Cristina Enes. Rod. João Leme dos Santos km 107 Condomínio Fazenda Imperial quadra F2 lote 13, Vereda dos Bandeirantes, 18052-765 Sorocaba, SP, Brazil. E-mail: cacenes@gmail.com

\section{Abstract}

Objective: To assess whether changes in dietary intake and physical activity pattern are associated with the annual body mass index (BMI) z-score change among adolescents. Methods: The study was conducted in public schools in the city of Piracicaba, Sao Paulo, Brazil, with a probabilistic sample of 431 adolescents participating in wave I (2004) (hereafter, baseline) and 299 in wave II (2005) (hereafter, follow-up). BMI, usual food intake, physical activity, screen time, sexual maturation and demographic variables were assessed twice. The association between annual change in food intake, physical activity, screen time, and annual BMI z-score changes were assessed by multiple regression. Results: The study showed a positive variation in BMI z-score over one-year. Among variables related to physical activity pattern only playing videogame and using computer increased over the year. The intake of fruits and vegetables and sugar-sweetened beverages increased over one year, while the others variables showed a reduction. An increased consumption of fatty foods ( $\beta=0.04, p=0.04$ ) and sweetened natural fruit juices ( $\beta=0.05, \mathrm{p}=0.03$ ) was positively associated with the rise in BMI z-score. Conclusions: Unhealthy dietary habits can predict the BMI z-score gain more than the physical activity pattern. The intake of fatty foods and sweetened fruit juices is associated with the BMI z-score over one year.

Keywords: Adolescent. Body mass index. Longitudinal studies. Motor activity. Food habits. 


\section{Resumo}

Objetivo: Avaliar se as mudanças no padrão alimentar e no padrão de atividade física estão associadas com mudança anual do escore-z do índice de massa corporal (IMC) entre os adolescentes. Métodos: $\mathrm{O}$ estudo foi realizado em escolas públicas de Piracicaba, São Paulo, Brasil, com uma amostra probabilística de 431 adolescentes participantes na onda I (2004) (doravante linha de base) e 299 na onda II (2005) (doravante seguimento). Nos dois momentos foram avaliados o IMC, a ingestão habitual de alimentos, atividade física, atividades sedentárias, maturação sexual e variáveis demográficas. A associação entre variação anual do consumo de alimentos, atividade física, atividades sedentárias e mudanças anuais do escore-z do IMC foi avaliada a partir de regressão múltipla. Resultados: $\mathrm{O}$ estudo mostrou uma variação positiva no escore-z do IMC ao longo de um ano. Entre as variáveis relacionadas ao padrão de atividade física apenas jogar videogame e usar o computador apresentou aumento ao longo do ano. A ingestão de frutas e legumes e de bebidas artificiais adoçadas aumentou ao longo de um ano e as demais variáveis apresentaram uma redução. Observou-se que o aumento do consumo de alimentos ricos em gordura $(\beta=0,04, p=0,04)$ e de suco natural adoçado $(\beta=0,05, p=0,03)$ associou-se positivamente ao aumento do escore-z do IMC. Conclusão: Hábitos alimentares não saudáveis predizem mais o aumento do escore-z do IMC do que o padrão de atividade física. A ingestão de alimentos ricos em gordura e de suco naturais adoçado associou-se positivamente ao escore-z do IMC ao longo de 1 ano.

Palavras-chave: Adolescente. Índice de massa corporal. Estudos longitudinais. Atividade motora. Hábitos alimentares.

\section{Introduction}

The rising prevalence of overweight and obesity among young people is a growing concern. In Brazil, $21.7 \%$ of adolescents are overweight ${ }^{1}$. Complications of youth overweight and obesity are well documented and include metabolic health risk, chronic diseases, psychosocial problems ${ }^{2,3}$, and increased risk of cardiovascular diseases in adulthood $^{4,5}$.

This rapid increase in obesity prevalence suggests that the role of environmental factors is more relevant than that of genetics factors $^{2,6}$. In fact, low, moderate and vigorous physical activity levels and high screen time levels among adolescents have been shown to be associated with obesity ${ }^{7}$. The value of physical activity as a treatment and preventive strategy for obesity has been demonstrated by substantial research ${ }^{8}$. Physical activity during the period from adolescence to adulthood can prevent adult obesity ${ }^{9}$.

In addition, several studies have reported the relationship between diet components, eating behaviors, and overweight among adolescents. The dietary patterns characterized by high intake of sugar and fats and low intake of fruits and vegetables are positively associated with weight gain in this group ${ }^{10-12}$. Hence, this study assessed whether changes in dietary intake, physical activity and screen time produce nutritional status changes among adolescents.

The strength of this study is that it simultaneously considers several factors related to energy intake and energy expenditure, while controlling for important covariates. To date we are not aware of any studies that have examined prospectively the role of dietary and physical activity factors and BMI z-score changes among Brazilian adolescents.

\section{Methods}

\section{Participants and study design}

A probabilistic sample of students was drawn from public schools of the city of 
Piracicaba, Sao Paulo, Southeastern Brazil. Piracicaba has around 368000 inhabitants ( $20 \%$ of them adolescents $)^{13}$ and shows a predominance of public schools, attended in most cases by children and adolescents from lower socioeconomic classes with some homogeneity in eating behavior. In the original research, a probabilistic sample covering all municipal students from public schools was drawn up in a two-stage cluster sample, stratified by school grade. In the first stage, the primary sampling units were all public schools and, in the second stage, the secondary sampling units comprised all school grades in each school. Further details of baseline sample procedures are provided elsewhere ${ }^{14}$.The study had 2 waves: the baseline was carried out from month 1 to month 2 in 2004 and the follow-up from month 1 to month 2 in 2005. The interval between two assessments was 12 months on average. In both moments, anthropometric measurements, sexual maturation, dietary intake, and physical activity pattern were assessed. At baseline (2004), 431 individuals (198 - 46\% boys, 233 - 54\% girls) were interviewed and the follow-up involved 299 subjects ( 135 - $45 \%$ boys, $164-55 \%$ girls); the age range was 10 to 15 years. The attrition rate was $30 \%$. The main reasons for follow-up losses were address, school, and phone number changes, which made tracking of adolescents more difficult. After the exclusion criteria were applied, the final sample included in the analysis totaled 256 students (113 - 44\% boys and $143-56 \%$ girls).

The Research Ethics Committee of the School of Public Health at the University of Sao Paulo approved the study proposal, and a signed informed consent form was obtained from the parents of adolescents.

\section{Anthropometric measurement}

All measurement procedures were performed according to the standardized procedures proposed by Lohman et al ${ }^{15}$. Height was measured to the nearest millimeter using a stadiometer, attached to the wall with no baseboards. Weight was measured using and electronic platform scale to the nearest $0.1 \mathrm{~kg}$ (Tanita HD316, Tokyo, Japan). Body mass index (BMI; kg/ $\mathrm{m}^{2}$ ) was calculated and converted to BMI z-scores using the recent World Health Organization (WHO) growth reference for school-aged children and adolescents ${ }^{16}$. BMI is often used as a surrogate for adiposity. BMI z-score was used rather than absolute BMI because doing so provided an indirect age- and sex-specific measure of relative adiposity. As adolescents experience substantial changes in body composition associated with growth and puberty, a relative measure of change in $\mathrm{BMI}$ is more appropriate than absolute BMI. One-year change in BMI z-score was computed (BMI z-score ${ }_{2005}$ - BMI z-score ${ }_{2004}$ ). A positive change in $\mathrm{z}$-score from baseline to follow-up indicates an increase in relative BMI over the time interval; a negative change in $\mathrm{z}$-score indicates a decrease in relative BMI. Any BMI and annual BMI change $>3$ SD (3 boys; 2 girls) and decrease in height between 2004 and 2005 (1 girl) were excluded. Additionally, participants without anthropometric measures in at least one interview (1 girl) were excluded.

\section{Dietary assessment}

Dietary intake was assessed by a semi-quantitative food-frequency questionnaire (FFQ). This instrument for youth and adolescents has been shown to be valid and reproducible ${ }^{17}$. The FFQ included questions regarding usual frequency of intake of 94 specific food items over the past six months. Composition data were analyzed using the Dietsys 4.01 software (National Cancer Institute, Bethesda, MD), which is specifically used to analyze food frequency questionnaire. Total fat intake (g/day) and consumption of specific food groups (servings/day) were estimated. Food groups considered in this analysis include: fruit and vegetables; sweets and added sugar; sweetened fruit juices (natural fruit juices added sugar); sugar-sweetened beverages (e.g. regular soda, coffee, sweetened iced 
tea, noncarbonated fruit drinks); fatty foods (such as pizza, snacks, French fries, pop corn, margarine). The total energy intake (kcal/day) was estimated and intakes $<500$ $\mathrm{kcal}$ or $>7000 \mathrm{kcal} /$ day (9 boys; 11 girls) were excluded as implausible ${ }^{18}$.

\section{Physical activity and screen time}

A validated questionnaire was used to assess habitual physical activity ${ }^{19}$. Participants were asked to recall the typical activities, number of times per week on average, time spent per session of activity, active transport (i.e. cycling and walking) and team sports over the past year. From each adolescent's responses, the physical activity per day (hours/day) (continuous variable) was computed. Estimates of physical activity that exceeded 40 hours / week ( 4 boys; 1 girl) were excluded from the analyses. To assess recreational inactivity, adolescents reported the number of hours spent daily with these activities, separated into weekdays and weekends ${ }^{6}$. From this information, each average adolescent's total hours per day (continuous variable) was computed. Totals $>80$ hours per week were excluded as unreliable ( 7 boys; 4 girls).

\section{Other measures}

Each adolescent's age was computed from his or her birth date and the date when the questionnaire was applied. The Tanner maturation stage was assessed by a validated self-rating of sexual maturity that uses categories/illustrations for secondary sexual characteristics as development of breasts and pubic hair in girls and the genitals and pubic hair in boys ${ }^{20}$. The time between study intervals was calculated by subtracting the baseline interview date from the follow-up interview date. Age and interval between study interviews (in months) were treated as continuous variables. Before beginning the main study, a pilot study was carried out with 19 adolescents and all questionnaires were tested, allowing adaptations to the final format of the questionnaires.
Questionnaires were double entered to assess inconsistencies.

\section{Statistical analysis}

First, the Kolmogorov-Smirnov test was used to evaluate the adherence of results to a normal distribution. Those with non-normal distribution were log transformed. Descriptive statistics (mean and standard deviation) were calculated for demographic, anthropometric and independent variables at baseline and follow-up. Using the baseline (2004) data, adolescents who did not finish the study were compared with those who did, using the unpaired t-test to assess potential follow-up bias. Paired t-test was used to test differences between baseline and follow-up. Only variables with a $P$-value lower than 0.20 in univariate analysis were included (Table 1). Multivariate stepwise linear regression was used to determine the relationship among changes in BMI z-score, dietary intake, physical activity and screen time. One-year changes in BMI z-score were the continuous outcome variable. Independent variables were the annual change in dietary intake, physical activity and screen time from 2004 to 2005. The final model was adjusted for baseline BMI z-score, baseline age, gender, interval between study interviews, change in sexual maturation (as dummy variable). Energy adjustments were made to control for confounding variables ${ }^{21}$. To see whether there was a modification effect by age and gender, the interaction between these variables and the independent variable was tested, using the $\mathrm{p}$-value as criteria for interaction. The statistical significance level was set at $5 \%$. The statistical analysis for the study was carried out using the Statistical Package for the Social Sciences 11.0 software (SPSS Institute Inc., Chicago, IL, USA).

\section{Results}

Of the 256 participants with complete questionnaires at both baseline and follow-up, $56 \%$ were girls. At baseline (2004) the 
Table 1 - Mean and standard deviation of variables for follow-up losses and cohort among adolescents. Piracicaba, SP, Brazil. 2004 - 2005.

Tabela 1 - Média e desvio-padrão das variáveis para as perdas de seguimento e coorte entre os adolescentes. Piracicaba. 2004-2005.

\begin{tabular}{lccc}
\hline Variables & $\begin{array}{c}\text { Follow-up losses } \\
(n=132)\end{array}$ & $\begin{array}{c}\text { Cohort } \\
(n=299)\end{array}$ & $p^{*}$ \\
\hline Age (years) & $12.6(1.8)$ & $12.1(1.3)$ & 0.007 \\
BMI (kg/m²) & $19.6(4.2)$ & $19.6(4.0)$ & 0.985 \\
Physical activity (h/day) & $1.3(1.25)$ & $1.4(1.62)$ & 0.701 \\
Screen time (h/day) & $4.3(3.6)$ & $4.5(3.2)$ & 0.555 \\
Energy (kcal/day) & $4077.3(1932.5)$ & $3883.9(1843.6)$ & 0.363 \\
Fat (g/day) & $154.4(84.5)$ & $147.9(81.8)$ & 0.486 \\
Fruits and vegetables (servings/day) & $5.2(3.7)$ & $5.1(3.1)$ & 0.711 \\
Sweets and added sugar (servings/day) & $4.5(2.4)$ & $4.2(2.3)$ & 0.235 \\
Sweetened fruit juice (servings/day) & $1.4(1.4)$ & $1.1(1.1)$ & 0.072 \\
Sugar-sweetened drinks (servings/day) & $2.1(1.3)$ & $1.8(1.2)$ & 0.033 \\
Fatty foods (servings/day) & $3.1(2.2)$ & $3.0(2.0)$ & 0.748 \\
\hline *Student'st test/*TesteTdeStudent & & &
\end{tabular}

mean age was 11.8 years; and at follow-up, 12.8 years (2005).

At baseline, $66.4 \%$ were classified as pubescent. A year later, this percentage rose to $87.6 \%$ (data not shown in tables).

Among adolescents who did not participate in the follow-up, $52.3 \%$ were girls. To compare the group of adolescents who finished the study with those who did not, the following variables were assessed: age, BMI, physical activity, energy, fat, fruit and vegetables, sweets and added sugar, sweetened fruit juices, sugar-sweetened beverages and fatty food intake (Table 1). There do not seem to be differences related to dietary intake, physical activity and BMI. However, those who did not finish the study were older $(\mathrm{p}<0.01)$ and consumed more sugar-sweetened beverages ( $p=0.03$ ). No modification effect by age and gender was observed from the interaction test.

Annual changes in dietary intake and physical activity pattern for adolescents were assessed (Table 2). A significant increase in computer use, videogame, fruits and vegetables, and sugar-sweetened beverages consumption was verified. In contrast, there was a significant decrease in energy, fat, sweets and added sugar, sweetened fruit juice, and fatty foods over one year. The annual change in BMI z-score was $0.1(\mathrm{p}<0.01)$.

A regression model was fit to assess whether changes in dietary habits, physical activity and screen time produce longitudinal BMI z-score changes among adolescents.

There was a significant positive association between sweetened fruit juice $(\mathrm{p}=0.03)$ and fatty food $(\mathrm{p}=0.04)$ intake and one-year change in BMI z-score. Adolescents who increased their fatty food intake by 1-serving/ day over the year had an increase in BMI $\mathrm{z}$-score, unlike those with an unchanged intake (Table 3).

In addition, the annual BMI z-score increase was higher in adolescents with a higher sweetened fruit juice intake. Although fat has not been significantly associated with changes in BMI z-score, it remained in the final model for adjustment.

No significant association was found between one-year change in BMI z-score and energy, fat, sweets and added sugar, sugar-sweetened beverages intake, screen time, and physical activity. 
Table 2 - One-year changes in dietary intake, and physical activity pattern. Piracicaba, SP, Brazil, 2004/2005.

Tabela 2 - Mudanças anuais na ingestão dietética e padrão de atividade física (Piracicaba, São Paulo, Brasil, 2004/2005).

\begin{tabular}{|c|c|c|c|c|c|c|c|}
\hline \multirow{2}{*}{$N=256$} & \multicolumn{2}{|c|}{ Baseline } & \multicolumn{2}{|c|}{ Follow-up } & \multirow{2}{*}{$\begin{array}{l}\text { Annual } \\
\text { change }\end{array}$} & \multirow{2}{*}{$\begin{array}{c}\text { SEb } \\
\text { mean }\end{array}$} & \multirow{2}{*}{$p$-valuec } \\
\hline & Mean & SDa & Mean & SD & & & \\
\hline Age (years) & 11.8 & 1.35 & 12.8 & 1.38 & 1.0 & 0.03 & $<0.01$ \\
\hline BMI z-score & 0.4 & 1.29 & 0.5 & 1.20 & 0.1 & 0.02 & $<0.01$ \\
\hline Physical activity (h/day) & 1.2 & 1.07 & 1.1 & 0.97 & -0.1 & 0.07 & 0.73 \\
\hline Television viewing (h/day) & 3.6 & 2.48 & 3.8 & 2.30 & 0.2 & 0.18 & 0.28 \\
\hline Playing video game (h/day) & 0.4 & 0.77 & 0.5 & 1.04 & 0.1 & 0.07 & 0.04 \\
\hline Using computer (h/day) & 0.2 & 0.61 & 0.5 & 0.97 & 0.3 & 0.05 & $<0.01$ \\
\hline Energy (kcal/day) & 2417.6 & 332.35 & 2358.9 & 328.48 & -58.7 & 23.48 & 0.01 \\
\hline Fat (g/day) & 92.9 & 5.46 & 89.7 & 4.64 & -3.2 & 0.42 & $<0.01$ \\
\hline Fruits and vegetables (servings/day) & 3.6 & 2.19 & 4.1 & 2.78 & 0.5 & 0.19 & 0.01 \\
\hline Sweets and added sugar (servings/day) & 3.2 & 1.53 & 2.8 & 1.57 & -0.4 & 0.13 & 0.01 \\
\hline Sweetened fruit juice (servings/day) & 2.2 & 0.77 & 1.8 & 0.90 & -0.4 & 0.07 & $<0.01$ \\
\hline Sugar-sweetened drinks (servings/day) & 0.7 & 1.00 & 1.2 & 0.94 & 0.5 & 0.08 & $<0.01$ \\
\hline Fatty foods (servings/day) & 2.8 & 0.90 & 1.6 & 1.12 & -1.2 & 0.09 & $<0.01$ \\
\hline
\end{tabular}

${ }^{\mathrm{a}}$ standard deviation; ${ }^{\mathrm{b}}$ standard error; ${ }^{\mathrm{c} P a i r e d ~ t-t e s t ~ / ~}{ }^{a}$ desvio-padrão; ${ }^{b}$ erro padrão; ${ }^{\mathrm{C} T e s t e}$ T pareado

Table 3 - Final results of the linear regression model§ to predict one-year change in BMI z-score.

Tabela 3 - Resultados finais do modelo de regressão linear múltiplo para predizer a mudança anual no escore Z do IMC.

\begin{tabular}{lccc}
\hline Independent variables & Parameter estimate $(\beta)$ & Confidence intervals $_{95 \%}$ & $p$-value \\
\hline$\Delta$ Fatty foods (servings/day) & 0.036 & $0.000 ; 0.072$ & 0.04 \\
$\Delta$ Fat (g/day) & 0.007 & $-0.002 ; 0.015$ & 0.11 \\
$\Delta$ Sweetened fruit juices (servings/day) & 0.053 & $0.004 ; 0.102$ & 0.03 \\
$\Delta$ Physical activity (h/day) & 0.017 & $-0.033 ; 0.068$ & 0.50 \\
$\Delta$ Television viewing (h/day) & -0.005 & $-0.025 ; 0.015$ & 0.62 \\
$\Delta$ Playing video game (h/day) & 0.006 & $-0.054 ; 0.066$ & 0.85 \\
$\Delta$ Using computer (h/day) & -0.025 & $-0.098 ; 0.047$ & 0.49 \\
\hline
\end{tabular}

§Model adjusted for baseline BMI z-score. Interval between study interviews. Gender. Sexual maturation. Baseline age. R2=0.19

$\S M o d e l o$ ajustado pelo Escore Z do IMC no baseline. Intervalo entre as entrevistas. Sexo. Maturação sexual. Idade no baseline. $R 2=0,19$

\section{Discussion}

The present longitudinal study showed that over one-year the effect of unhealthy dietary habits on BMI z-score gain is greater compared to the physical activity pattern. This measure was used in other studies that also had the purpose to assess the role of dietary intake ${ }^{22}$ and physical activity pattern $^{23}$ in changes in BMI z-score. The use of annual change in BMI z-score as a dependent variable had the advantage of avoiding arbitrary cut-off points to define obesity. Thus, misclassification of obesity was avoided.

Adolescents who increased their fatty food and sweetened fruit juice intake had an increase in BMI z-score in the same period. Although the estimated magnitudes of these effects have not been very high, their cumulative effects, year after year, may produce substantial gains in BMI z-score. Physical activity and screen time were not associated with BMI z-score changes over one year.

The findings of this study are consistent with other studies ${ }^{10,11,24}$ that provide 
evidence that fatty foods consumption is related to longitudinal changes in body fatness. It is possible that the effect of fatty foods on the BMI z-score gain is due to their high energy density, associated with low nutrient contents. In addition, the flavor of these foods may promote weight gain by promoting excessive consumption. Some studies have also shown that the power of satiety of fats is lower compared to carbohydrates and proteins, making it more difficult to adjust compensation after a meal rich in fat, which is directly related to excessive energy consumption ${ }^{25,26}$. In addition, dietary fat is stored more efficiently than carbohydrate and protein ${ }^{27}$.

Furthermore, there was a positive association between sweetened fruit juice and BMI z-score changes, whereas no significant relationship was observed between sugar-sweetened beverages intake and BMI z-score. This could be explained by the greater energy density of natural sweetened fruit juices compared to sugar-sweetened beverages (including soft drinks). Thus, the discrepancy in the supply of energy considering both groups may explain the effect of consumption of sweetened natural fruit juices on changes in BMI z-score.

In a case-control study, Tanasescu et al. ${ }^{28}$ found a positive association between fruit juice intake and a measure of adiposity. In a five-year longitudinal study, Libuda et al. ${ }^{29}$ found that fruit juice intake $(100 \%$ juice) was also associated with weight gain among youths from Germany. In contrast, other investigations that prospectively analyzed the relationship between fruit juice intake and obesity found no association $^{30,31}$. In a cross-sectional study, adolescents consuming $100 \%$ juice did not show mean increased weight measures ${ }^{32}$. It is important to note that most investigations analyzed have considered $100 \%$ fruit juice with no added sugar.

Further evaluation of the effect of fruit juice intake on weight is warranted because natural fruit juice remains an important source of vitamins and minerals, particularly for children. Thus, a healthy alternative could be the consumption of fruit juices with no added sugar.

There was no evidence that fruit and vegetable intake was associated with changes in BMI z-score. Several studies also found no association between fruit and vegetable intake and childhood adiposity ${ }^{33-35}$. Studies that found an inverse relationship between fruit or fruit and vegetable intake and adiposity tended to have a larger sample size, compared with those that found no association ${ }^{36}$. Although the findings available in the literature are still conflicting, it is important to highlight the crucial role of fruits and vegetables in health promotion.

Although there is some evidence supporting a strong association between physical activity patterns and obesity in adults, it is important to note that the relationship between physical activity and inactivity and adiposity in youth has not been clearly established. There were no longitudinal associations between physical activity, screen time, and BMI z-score changes, and even publications point to contradictory results ${ }^{37-40}$

The present study has some limitations. The first one is the loss of follow-up that led to an important reduction in sample size. Although the analysis of bias gives evidence that the loss did not affect the final result, the sample size reduction may have hindered the identification of associations. Furthermore, the time period studied herein (12 months) may not be sufficient to produce important changes in behavior and BMI z-score. Finally, the determination coefficient of the model explains only $19 \%$ of the annual change of BMI z-score. There are other variables, not considered in this study, such as socioeconomic level and maternal education, that could explain the variation in BMI z-score.

The lack of associations between physical activity/sedentary behavior and BMI z-score change may be also explained from other perspectives. Physical activity among youths is challenging to be measured because the capacity to understand and to recall the concepts of time, duration, and intensity 
of past activity is associated inversely with age. Measuring leisure activities accurately is difficult because of great inter- and intra-individual variation in activities and their temporal patterns ${ }^{40}$.

In conclusion, unhealthy dietary habits predict the BMI z-score gain more than physical activity pattern. This study, although not fully explaining the associations of complex dietary intake and physical pattern with BMI z-score, suggest that public health strategies to reduce the consumption of fatty foods such as pizzas, French fries and pop corn and to encourage the consumption of natural fruit juice with no added sugar should be promoted to prevent excessive annual increases in BMI z-score among adolescents. Future longitudinal investigations are still needed to establish the role that dietary and physical activity pattern play in nutritional status changes.

Acknowledgments: The authors would like to thank the State of São Paulo Research Support Foundation (FAPESP) for the financial resources granted (process 02/9521-9).

Conflicts of interest: The authors declare that there are no conflicts of interest related to this article.

\section{References}

1. Brasil, 2010. Instituto Brasileiro de Geografia e Estatística - IBGE. Pesquisa de Orçamentos Familiares 2008-2009: antropometria e estado nutricional de crianças, adolescentes e adultos no Brasil. [on line]. Rio de Janeiro; 2010. Available at http//www.ibge.gov.br/ (Acessed Jan 06, 2011).

2. Ebbeling CB, Pawlak DB, Ludwig DS. Childhood obesity: public health crisis, common sense cure. Lancet 2002; 360: 473-82.

3. Ludwig DS. Childhood obesity-The shape of things to come. N Engl J Med 2007; 357: 2325-27.

4. Baker JL, Olsen LW, Sorensen TIA. Childhood bodymass index and the risk of coronary heart disease in adulthood. N Engl J Med 2007;357: 2329-37.

5. Bibbins-Domingo K, Coxson P, Pletcher MJ, Lightwood J, Goldman L. Adolescent overweight and future adult coronary heart disease. N Engl J Med 2007; 357: 2371-79.

6. Berkey CS, Rockett HRH, Field AE, Gillman MW, Frazier AL, Camargo CA et al. Activity, dietary intake, and weight changes in a longitudinal study of preadolescents and adolescents boys and girls. Pediatrics 2000; 105: 56-66.

7. Must A, Bandini LG, Tybor DJ, Phillips SM, Naumova EN, Dietz WH. Activity, inactivity, and screen time in relation to weight and fatness over adolescence in girls. Obesity 2007; 15: 1774-81.

8. Janiszewski PM, Ross R. Physical activity in the treatment of obesity: beyond body weight reduction. Appl Phys Nutr Metab 2007; 32: 512-22.

9. Tammelin T, Laitinen J, Nayha S. Change in the level of physical activity from adolescence into adulthood and obesity at the age of 31 years. Int J Obes Relat Disord 2008; 28: 775-82.
10. Drapeau V, Despres JP, Bouchard C, Allard L, Fournier G, Leblanc C, et al. Modifications in food-group consumption are related to long-term body-weight changes. Am J Clin Nutr 2004; 80: 29-37.

11. Taveras EM, Berkey CS, Rifas-Shiman SL, Ludwig DS, Rockett HRH, Field AE et al. Association of consumption of fried food away from home with body mass index and diet quality in older children and adolescents. Pediatrics 2005; 116: 18-24.

12. American Dietetic Association. (2006). Childhood overweight evidence analysis project: updated. Available at www.asaevidencelibrary.com/topic.cfm?cat=1046 (Accessed May 10, 2008).

13. State System Foundation of Data Analyze (SEADE). Population and vital statistics: information from Sao Paulo's cities. Available at http://www.seade.gov.br/ produtos/imp/ (Accessed March 14, 2011).

14. Toral N, Slater B. Perception of eating practices and stages of change among Brazilian adolescents. Prev Med 2009; 48: 279-83.

15. Lohman TG, Roche AF, Martorell R (eds.). Anthropometric standardization reference manual. Champaign (IL): Human Kinetics Books; 1988.

16. De Onis M, Onyango AW, Borghi E, Siyam A, Nishida C, Siekmann J. Development of a WHO growth reference for school-aged children and adolescents. Bull World Health Org 2007; 5 :660-67.

17. Slater B, Fisberg RM, Philippi ST, Latorre MRO. Validation of a semi-quantitative adolescent food frequency questionnaire applied at a public school in São Paulo, Brazil. Eur J Clin Nutr 2003; 57: 629-35. 
18. Ludwig DS, Peterson KE, Gortmaker SL. Relation between consumption of sugar-sweetened drinks and childhood obesity: a prospective, observational analysis. Lancet 2001; 357: 505-8.

19. Florindo AA, Romero A, Peres SV, Silva MV, Slater B. Development and validation of a physical activity assessment questionnaire for adolescents. Rev Saúde Publica 2006; 40: 802-9.

20. Tanner JM. Growth at Adolescence. $2^{\text {nd }}$ ed. Oxford: Blackwell Scientific Publications; 1962.

21. Willett WC, Howe GR, Kushi LH. Adjustment for total energy intake in epidemiologic studies. Am J Clin Nutr 1997; 65(S): 1220-8S.

22. Thompson OM, Ballew C, Resnicow K, Gillespie C, Must A, Bandini LG et al. Dietary pattern as a predictor of change in BMI z-score among girls. Int J Obes 2006; 30: 176-182.

23. Timperio A, Salmon JO, Ball K, Baur LA, Telford A, Jackson $\mathrm{M}$ et al. Family activity and sedentary environments and weight change in children. Int $J$ Pediatr Obes 2008; 3: 160-7.

24. Bes-Rastrollo M, Sánchez-Villegas A, Gómez-Gracia E, Martínez JÁ, Pajares RM, Martínez-González MA. Predictors of weight gain in a Mediterranean cohort: the Seguimiento Universidad de Navarra Study. Am J Clin Nutr 2006; 83: 362-70.

25. Stubbs RJ, van Wyk MCW, Johnstone AM, Harbron CG. Breakfasts high in protein, fat or carbohydrate: effect on within-day appetite and energy balance. Eur J Clin Nutr 1996; 50: 409-17.

26. Maffeis C, Surano MG, Cordioli S, Gasperotti S, Corradi M, Pinelli L. A High-fat vs. a Moderate-fat Meal in Obese Boys: Nutrient Balance, Appetite, and Gastrointestinal Hormone Changes. Obesity 2010; 18: 449-55.

27. Poppitt SD. Energy density of diets and obesity. Int J Obes 1995; (S19): 20-6.

28. Tanasescu M, Ferris AM, Himmelgreen DA, Rodriguez N, Pérez-Esamilla R. Biobehavioral factors are associated with obesity in Puerto Rican children. J Nutr 2000; 30: 1734-42.

29. Libuda L, Alexy U, Sichert-Hellert W, Stehe P, KaraolisDanckert N, Buyken AE et al. Pattern of beverage consumption and long-term association with body status in German adolescents - results from the DONALD study. Br J Nutr 2008; 99: 1370-9.
30. Berkey CS, Rockett HRH, Field AE, Gillman MW, Colditz GA. Sugar-added beverages and adolescent weight change. Obes Res 2004; 12: 778-88.

31. Newby PK, Peterson KE, Berkey CS, Leppert J, Willett WC, Colditz GA. Beverages consumption is not associated with changes in weight and body mass index among low-income preschool children in North Dakota. J Am Diet Assoc 2004; 10: 1086-94.

32. O’Neil CE, Nicklas TA, Kleinman R. Relationship between $100 \%$ juice consumption and nutrient intake and weight of adolescents. Am J Health Promot 2010; 24: 231-7.

33. Field AE, Gillman MW, Rosner B, Rockett HR, Colditz GA. Association between fruit and vegetable intake and change in body mass index among a large sample of children and adolescents in the United States. Int J Obes 2003; 27: 821-6.

34. Newby PK, Muller D, Hallfrisch J, Qiao N, Andres R, Tucker KL. Dietary patterns and changes in body mass index and waist circumference in adults. Am J Clin Nutr 2003; 77: 1417-25.

35. Sugimori H, Yoshida K, Izuno T, Miyacawa M, Suka M, Sekine M, et al. Analysis of factors that influence body mass index from ages 3 to 6 years: a study based on the Toyama Cohort Study. Pediatric Int 2004; 46: 302-10.

36. Davis MM, Gance-Cleveland B, Hassink S, Johnson R, Paradis G, Resnicow K. Recommendations for prevention of childhood obesity. Pediatrics 2007; 120(S): 229-53.

37. Berkey CS, Rockett HRH, Gillman MW, Colditz GA. Oneyear changes in activity and in inactivity among 10-to 15-year-old boys and girls: relationship to change in body mass index. Pediatrics 2003; 111: 836-43.

38. Viner RM, Cole TJ. Television viewing in early childhood predicts adult body mass index. J Pediatr 2005; 147: 42935 .

39. Laurson K, Eisenmann JC, Moore S. Lack of association between television viewing, soft drinks, physical activity and body mass index in children. Acta Paediatrica 2008; 97: 795-800.

40. Lajunen H, Keski-Rahkonen A, Pulkkinen L, Rose RJ, Rissanen A, Kaprio J. Leisure activity patterns and their associations with overweight: A prospective study among adolescents. J Adolescence 2009; 32: 1089-1103.

Recebido em: 01/09/12 Versão final apresentada em: 20/08/12 Aprovado em: $31 / 10 / 12$ 